\title{
Impact of Lymphovascular Invasion in Patients With Stage II Colorectal Cancer: A Propensity Score-matched Study
}

\author{
MASAHIRO KATAOKA, YASUMITSU HIRANO, TOSHIMASA ISHII, HIROKA KONDO, \\ MASAHIRO ASARI, SHINTARO ISHIKAWA, ATSUKO KATAOKA, \\ TAKATSUGU FUJII, SATOSHI SHIMAMURA and SHIGEKI YAMAGUCHI
}

Department of Gastrointestinal Surgery, Saitama Medical University International Medical Center, Saitama, Japan

\begin{abstract}
Background/Aim: Whether lymphovascular invasion (LVI) is a high-degree risk factor in stage II colorectal cancer has not been fully clarified, as different results have been reported in the literature. If LVI is a risk factor, postoperative chemotherapy may be recommended. The purpose of this study was to evaluate the impact of lymphovascular invasion on disease recurrence and patient prognosis in conjunction with stage II colorectal cancer (CRC). Patients and Methods: A total of 636 patients with stage II CRC, each undergoing radical resection between April 2007 and December 2015, were selected for the study. Subjects with or without venous or lymphatic invasion were assigned to positive and negative groups, respectively. We then compared overall survival $(O S)$ and disease-free survival (DFS) using propensity score matching. Results: After matching ( $n=226$, each group), $O S$ and DFS were found to be significantly lower (OS: $p=0.047 ;$ DFS: $p=0.004$ ) in patients positive (vs. negative) for venous invasion. However, the same was not true of lymphatic invasion. After matching, positive and negative groups $(n=92$, each) did not significantly differ in terms of OS ( $p=0.951)$ or DFS ( $p=0.258)$. Conclusion: In patients with stage II CRC, venous invasion proved to be a significant high-degree risk factor that may warrant adjuvant chemotherapy.
\end{abstract}

The Union for International Cancer Control (UICC) stipulates that infiltration of colorectal cancer (CRC) beyond

This article is freely accessible online.

Correspondence to: Masahiro Kataoka, Department of Gastrointestinal Surgery, Saitama Medical University International Medical Center, 1397-1, Yamane, Hidaka, Saitama, Japan. Tel: +81 429844111, Fax: +81 429840054, e-mail: ksta0926@sitama-med.ac.jp

Key Words: Lymphovascular invasion, high-risk factor, stage II colorectal cancer, adjuvant chemotherapy. muscularis propria in the absence of lymph node metastasis qualifies as stage II disease. This is insufficient basis for routine postoperative adjuvant chemotherapy in Japan (1). Although both the American Society of Clinical Oncology (ASCO) and the European Society for Medical Oncology (ESMO) guidelines advise such treatment if there are highdegree risk factors for recurrence $(2,3)$, the definitions of high recurrence risk patently differ. Lymphovascular invasion (LVI), signified by tumor cells within endotheliallined spaces, is considered a high-risk factor for stage II CRC recurrence by ESMO, but not by ASCO guidelines.

LVI encompasses lymphatic as well as venous invasion. At present, it is unclear whether the full spectrum of LVI carries a poor prognosis in the setting of stage II CRC (4-7). It would be of immense value to determine whether each component separately confers an ominous prognosis, thus allowing more selective administration of adjuvant chemotherapy. This study was conducted to evaluate the respective effects of venous and lymphatic invasion on overall survival (OS) and disease-free survival (DFS) rates in patients with radically resected stage II CRC, using propensity score matching.

\section{Patients and Methods}

As a retrospective effort, we reviewed data on 652 patients undergoing surgical resections for stage II CRC between April 2007 and December 2015 at the Saitama Medical University International Medical Center. Those with recurrent CRC, synchronous malignancy, or squamous cell carcinoma were excluded, leaving 636 for analysis. Written informed consent was granted by all subjects, and the Ethics Committee at the center approved our study protocol. Two pathologists evaluated all CRC specimens. Resected tumors were classified using the UICC ( $8^{\text {th }}$ edition) TNM system and discretionary immunohistochemistry.

All statistical computations were powered by the EZR freeware (R Foundation for Statistical Computing, Vienna, Austria). We used propensity score matching to overcome bias in differing group distributions. A 1:1 match without replacement was performed through nearest available matching, with caliper set at 0.2. Each patient was propensity scored, based on a logistic regression model 


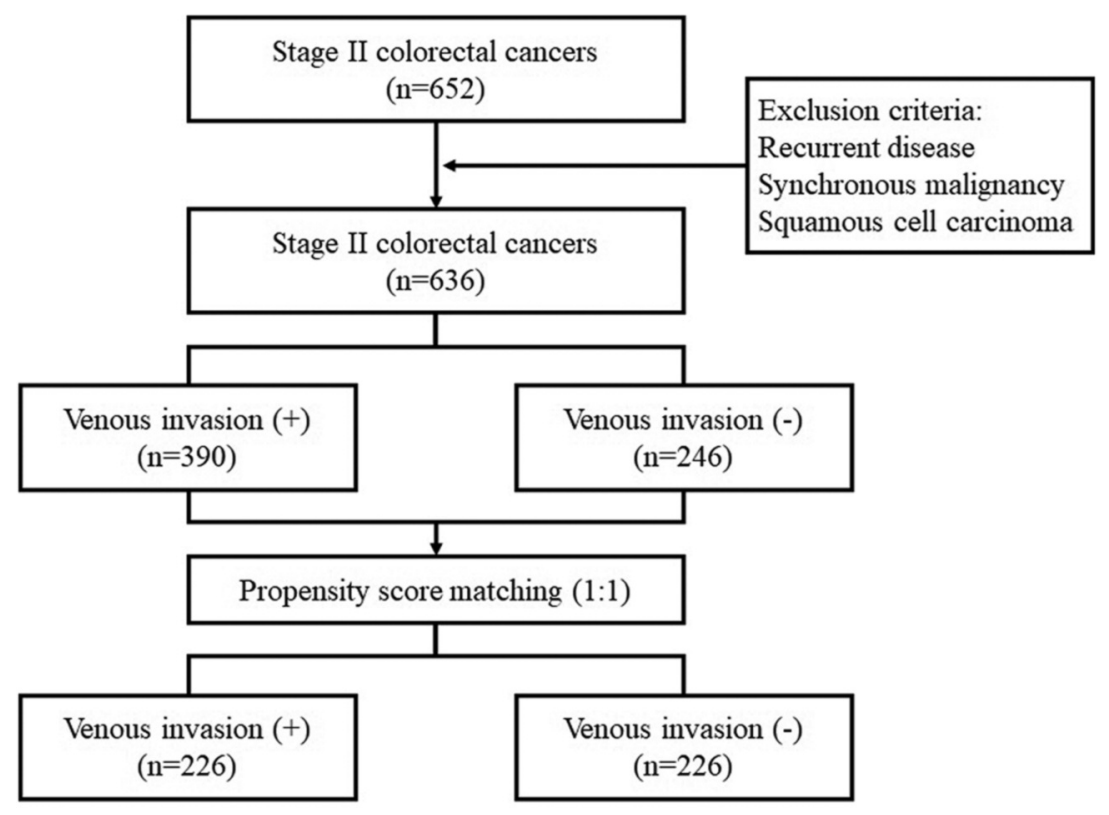

Figure 1. Algorithm for analysis of venous invasion.

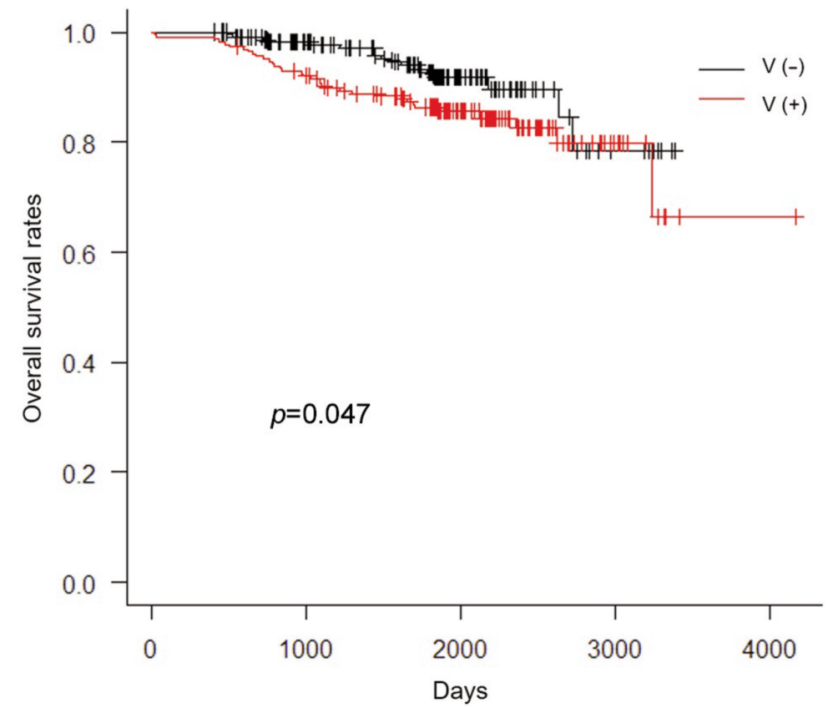

Figure 2. Overall survival in patients with stage II CRC, positive (+) or negative (-) for venous invasion.

addressing the following eight covariates: sex, age, American Society of Anesthesiologists physical status (ASA-PS), tumor location, tumor histotype, lymphatic or venous invasion, infiltrative depth, and adjuvant chemotherapy. After matching, logistic regression analysis was invoked to determine survival differences of groups positive and negative for venous or lymphatic invasion. Differences in categorical variables were tested by Chi-squared or Fisher's exact test, and survival rates (OS, DFS) were estimated via Kaplan-Meier method. Significance was set at $p<0.05$.

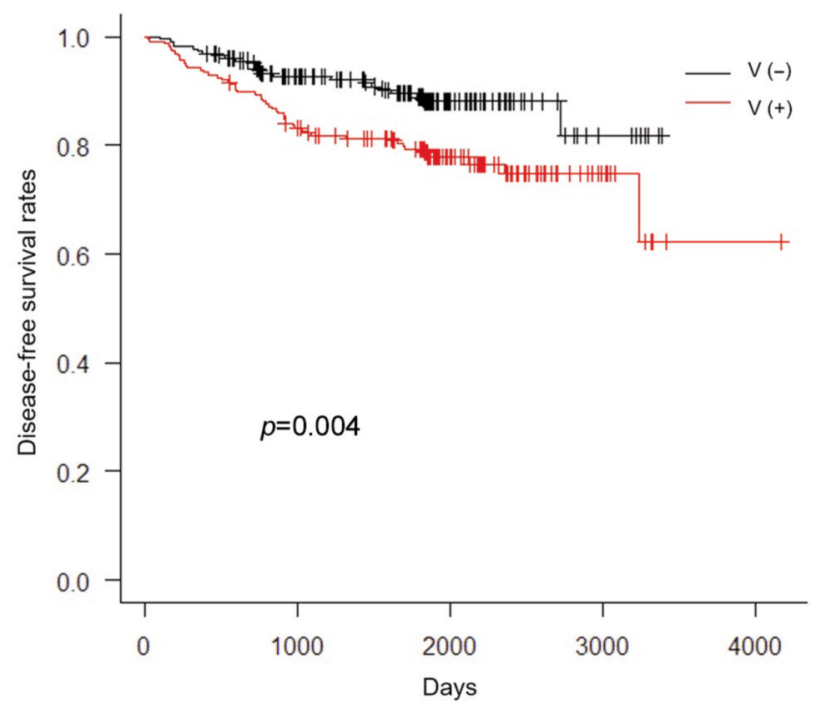

Figure 3. Disease-free survival in patients with stage II CRC, positive (+) or negative (-) for venous invasion.

\section{Results}

A total of 636 patients with stage II CRC patients were selected for the study. Venous invasion was detected in 390 $(61.3 \%)$ patients, and lymphatic invasion was evident in 94 $(17.3 \%)$.

Initially, a single-factor analysis of patients with $(\mathrm{n}=390)$ and without $(\mathrm{n}=246)$ venous invasion was performed. In 
Table I. Clinicopathologic parameters of stage II CRC pertaining to venous invasion.

\begin{tabular}{|c|c|c|c|c|c|c|}
\hline \multirow[b]{2}{*}{ Variable } & \multicolumn{3}{|c|}{ Before PSM } & \multicolumn{3}{|c|}{ After PSM } \\
\hline & Venous invasion $(+)$ & Venous invasion (-) & $p$-Value & Venous invasion (+) & Venous invasion (-) & $p$-Value \\
\hline Gender, $\mathrm{n}$ & 390 & 246 & & 226 & 226 & \\
\hline Male & $237(60.8 \%)$ & $143(58.1 \%)$ & & $141(62.4)$ & $137(60.6)$ & \\
\hline Female & $153(39.2 \%)$ & $103(41.9 \%)$ & 0.561 & 85 (37.6) & $89(39.4)$ & 0.772 \\
\hline Age, years & $67.96 \pm 10.48$ & $68.35 \pm 10.89$ & 0.654 & $69.01 \pm 10.58$ & $68.35 \pm 10.91$ & 0.509 \\
\hline \multicolumn{7}{|l|}{ ASA-PS } \\
\hline 1 & $130(33.3 \%)$ & $86(35.0 \%)$ & & $78(34.5 \%)$ & $80(35.4 \%)$ & \\
\hline 2 & $229(58.7 \%)$ & $138(56.1 \%)$ & & $132(58.4 \%)$ & $125(55.3 \%)$ & \\
\hline 3 & $30(7.7 \%)$ & $22(8.9 \%)$ & & $15(6.6 \%)$ & $21(9.3 \%)$ & \\
\hline 4 & $1(0.3 \%)$ & $0(0.0 \%)$ & 0.838 & $1(0.4 \%)$ & $0(0.0 \%)$ & 0.550 \\
\hline \multicolumn{7}{|l|}{ Tumor location } \\
\hline Colon & $236(60.5 \%)$ & $162(65.9 \%)$ & & $148(65.5 \%)$ & $147(65.0 \%)$ & \\
\hline Rectum & $154(39.5 \%)$ & $84(34.1 \%)$ & 0.180 & $78(34.5 \%)$ & $79(35.0 \%)$ & 1.000 \\
\hline \multicolumn{7}{|l|}{ Tumor histotype } \\
\hline $\begin{array}{l}\text { Well-, moderately } \\
\text { differentiated }\end{array}$ & $368(94.4 \%)$ & $207(84.1 \%)$ & & $205(90.7 \%)$ & $207(91.6 \%)$ & \\
\hline Other & $22(5.6 \%)$ & $39(15.9 \%)$ & $<0.001$ & $21(9.3 \%)$ & $19(8.4 \%)$ & 0.869 \\
\hline \multicolumn{7}{|l|}{ Lymphatic invasion } \\
\hline No & $327(83.8 \%)$ & $215(87.4 \%)$ & & $188(83.2 \%)$ & $199(88.1 \%)$ & \\
\hline Yes & $63(16.2 \%)$ & $31(12.6 \%)$ & 0.252 & $38(16.8 \%)$ & $27(11.9 \%)$ & 0.180 \\
\hline \multicolumn{7}{|l|}{ Infiltrative depth } \\
\hline $\mathrm{T} 3$ & $351(90.0 \%)$ & $222(90.2 \%)$ & & $210(92.9 \%)$ & $206(91.2 \%)$ & \\
\hline $\mathrm{T} 4$ & $39(10.0 \%)$ & $24(9.8 \%)$ & 1.000 & $16(7.1 \%)$ & $20(8.8)$ & 0.603 \\
\hline \multicolumn{7}{|c|}{ Adjuvant chemotherapy } \\
\hline No & $382(97.9 \%)$ & $237(96.3 \%)$ & & $222(98.2 \%)$ & $222(98.2 \%)$ & \\
\hline Yes & $8(2.1 \%)$ & $9(3.7 \%)$ & 0.312 & $4(1.8 \%)$ & $4(1.8 \%)$ & 1.000 \\
\hline
\end{tabular}

CRC, Colorectal cancer; PSM, propensity score matching; ASA-PS, American Society of Anesthesiologists physical status.

patients positive ( $v s$. negative) for venous invasion, the percentage of well- or moderately differentiated tubular adenocarcinoma was significantly greater $(94.4 \%$ vs. $84.1 \%$; $p<0.001)$. Otherwise, no significant differences were observed with respect to male sex $(60.8 \%$ vs. $58.1 \%$; $p=0.561)$, age $(67.96 \pm 10.48$ vs. $68.35 \pm 10.89 ; p=0.654)$, ASA-PS ( $p=0.838$ ), tumor location (colon: $60.5 \%$ vs. $65.9 \%$; $p=0.180)$, incidence of lymphatic invasion $(16.2 \% \mathrm{vs} .12 .6 \%$; $p=0.252$ ), deep infiltration (T4: $10.0 \% v s .9 .8 \% ; p=1.000)$, or adjuvant chemotherapy $(2.1 \% v s .3 .7 \% ; p=0.312)$.

The two groups were then matched by propensity scores (1:1 ratio), each yielding 229 patients (Figure 1) with similarities of gender, age, ASA-PS, tumor location, tumor histotype, lymphatic invasion, infiltrative depth, and adjuvant chemotherapy (Table I).

Five-year OS rates in groups positive and negative for venous invasion were $86.3 \%$ (95\% $\mathrm{CI}=81.0-90.3)$ and $91.8 \%$ (95\% CI=86.5-95.1), respectively $(p=0.047)$ (Figure 2). Corresponding 5-year DFS rates were 79.3\% (95\% CI=73.4$84.1)$ and $88.0 \%(95 \% \mathrm{CI}=82.4-92.0)$, respectively $(p=0.004)$ (Figure 3). Patient prognosis was thus poorer in the in the presence of venous invasion.
We then subjected patients with $(n=94)$ and without $(n=542)$ lymphatic invasion to single-factor analysis. In those showing lymphatic invasion, tumors more often involved the colon rather than rectum $(72.3 \%$ vs. $60.9 \%$; $p<0.038)$. No significant differences were encountered with respect to male sex $(57.4 \%$ vs. 60.1\%; $p=0.649)$, age $(69.69 \pm 10.05 v s$. $67.83 \pm 10.72 ; p=0.118)$, ASA-PS ( $p=0.359)$, tumor histotype (well- or moderately differentiated: $88.3 \%$ vs. $90.8 \%$; $p=0.449)$, incidence of venous invasion $(67.0 \% \mathrm{vs} .60 .3 \%$; $p=0.252$ ), deep infiltration (T4: $14.9 \%$ vs. $9.0 \% ; p=0.092$ ), or adjuvant chemotherapy $(5.3 \%$ vs. $2.2 \% ; p=0.091)$. The two groups were also matched by propensity scores $(1: 1$ ratio), each comprised of 92 patients (Figure 4). All paired covariates were well balanced, showing no significant differences (Table II).

Five-year OS rates in groups positive and negative for lymphatic invasion were $82.6 \%$ (95\% CI=71.0-89.9) and $84.7 \%$ (95\% CI=74.5-91.1), respectively ( $p=0.951$ ) (Figure 5). Corresponding 5-year DFS rates were $70.3 \%(95 \%$ $\mathrm{CI}=58.2-79.5)$ and $78.3 \%(95 \% \mathrm{CI}=67.5-85.8)$, respectively $(p=0.258)$ (Figure 6). On the basis of lymphatic invasion, OS and DFS did not differ significantly. 


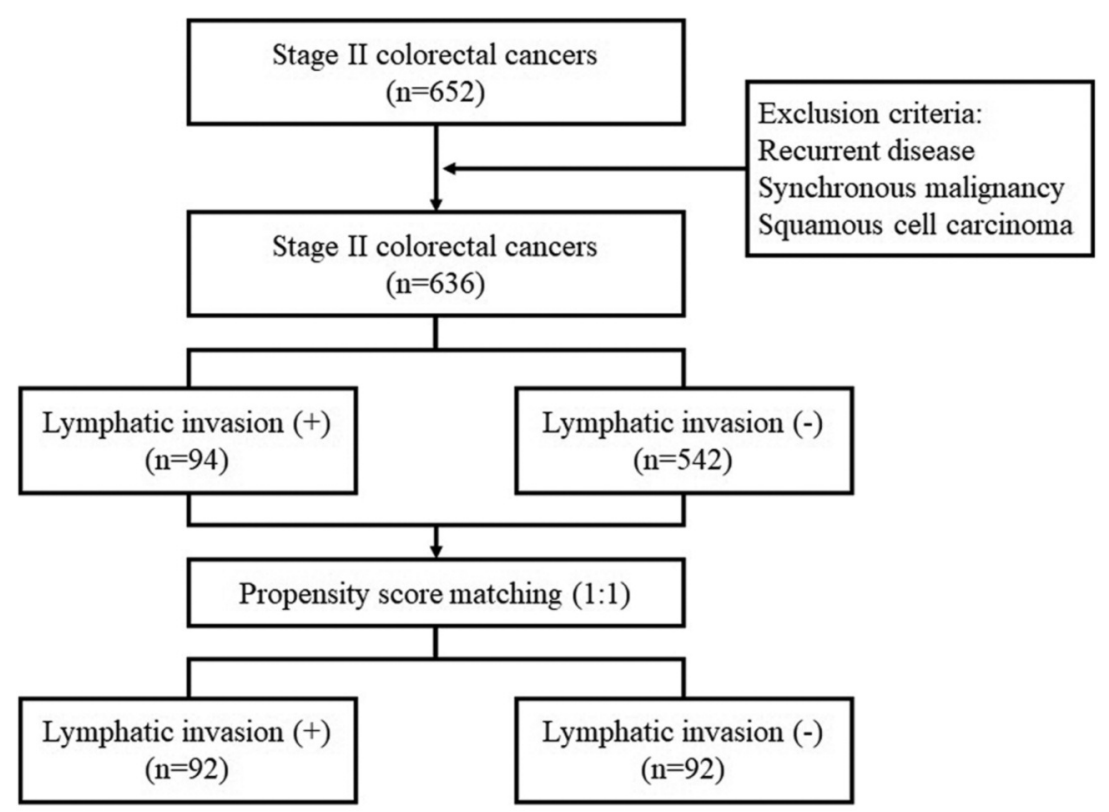

Figure 4. Disease-free survival in patients with stage II CRC, positive (+) or negative (-) for venous invasion.

Table II. Clinicopathological parameters of stage II CRC pertaining to lymphatic invasion.

\begin{tabular}{|c|c|c|c|c|c|c|}
\hline \multirow[b]{2}{*}{ Variable } & \multicolumn{3}{|c|}{ Before PSM } & \multicolumn{3}{|c|}{ After PSM } \\
\hline & Lymphatic invasion (+) & Lymphatic invasion (-) & $p$-Value & Lymphatic invasion (+) & Lymphatic invasion (-) & $p$-Value \\
\hline Gender, $\mathrm{n}$ & 94 & 542 & & 92 & 92 & \\
\hline Male & $54(57.4 \%)$ & $326(60.1 \%)$ & & $54(58.7 \%)$ & $56(60.9 \%)$ & \\
\hline Female & $40(42.6 \%)$ & $216(39.9 \%)$ & 0.649 & $38(41.3 \%)$ & $36(39.1 \%)$ & 0.881 \\
\hline Age, yr & $69.69 \pm 10.05$ & $67.83 \pm 10.72$ & 0.118 & $69.46 \pm 9.93$ & $70.21 \pm 9.89$ & 0.608 \\
\hline \multicolumn{7}{|l|}{ ASA-PS } \\
\hline 1 & $25(26.6 \%)$ & $191(35.2 \%)$ & & $24(26.1 \%)$ & $26(28.3 \%)$ & \\
\hline 2 & $61(64.9 \%)$ & $306(56.5 \%)$ & & $60(65.2 \%)$ & $57(62.0 \%)$ & \\
\hline 3 & $8(8.5 \%)$ & $44(8.1 \%)$ & & $8(8.7 \%)$ & $9(9.8 \%)$ & \\
\hline 4 & $0(0.0 \%)$ & $1(0.2 \%)$ & 0.359 & $0(0.0 \%)$ & $0(0.0 \%)$ & 0.898 \\
\hline \multicolumn{7}{|l|}{ Tumor location } \\
\hline Colon & $68(72.3 \%)$ & $330(60.9 \%)$ & & $66(71.7 \%)$ & $69(75.0 \%)$ & \\
\hline Rectum & $26(27.7 \%)$ & $212(39.1 \%)$ & 0.038 & $26(28.3 \%)$ & $23(25.0 \%)$ & 0.739 \\
\hline \multicolumn{7}{|l|}{ Tumor histotype } \\
\hline $\begin{array}{l}\text { Well-, moderately } \\
\text { differentiated }\end{array}$ & $83(88.3 \%)$ & $492(90.8 \%)$ & & $81(88.0 \%)$ & $82(89.1 \%)$ & 1.000 \\
\hline Other & $11(11.7 \%)$ & $50(9.2 \%)$ & 0.449 & $11(12.0 \%)$ & $10(10.9 \%)$ & \\
\hline \multicolumn{7}{|l|}{ Venous invasion } \\
\hline No & $31(33.0 \%)$ & $215(39.7 \%)$ & & $31(33.7 \%)$ & $29(31.5 \%)$ & \\
\hline Yes & $63(67.0 \%)$ & $327(60.3 \%)$ & 0.252 & $61(66.3 \%)$ & $63(68.5 \%)$ & 0.875 \\
\hline \multicolumn{7}{|l|}{ Infiltrative depth } \\
\hline $\mathrm{T} 3$ & $80(85.1 \%)$ & $493(91.0 \%)$ & & $80(87.0 \%)$ & $82(89.1 \%)$ & \\
\hline $\mathrm{T} 4$ & $14(14.9 \%)$ & $49(9.0 \%)$ & 0.092 & $12(13.0 \%)$ & $10(10.9 \%)$ & 0.821 \\
\hline \multicolumn{7}{|c|}{ Adjuvant chemotherapy } \\
\hline No & $89(94.7 \%)$ & $530(97.8 \%)$ & & $88(95.7 \%)$ & $90(97.8 \%)$ & \\
\hline Yes & $5(5.3 \%)$ & $12(2.2 \%)$ & 0.091 & $4(4.3 \%)$ & $2(2.2 \%)$ & 0.682 \\
\hline
\end{tabular}

CRC, Colorectal cancer; PSM, propensity score matching; ASA-PS, American Society of Anesthesiologists physical status. 


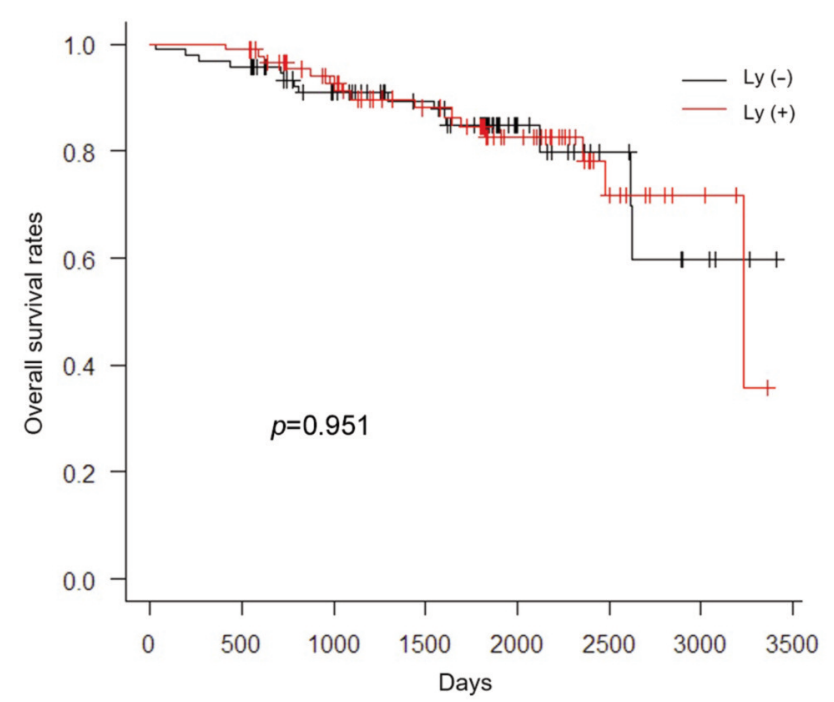

Figure 5. Overall survival in patients with stage II CRC, positive (+) or negative (-) for lymphatic invasion.

\section{Discussion}

In early-stage CRC, particularly at stage II, postoperative administration of adjuvant chemotherapy is controversial $(4,5)$. Results from clinical trials have shown no significant differences in recurrence or survival rates recorded for surgically treated stage II CRC, with or without adjuvant chemotherapy $(4,6,7)$. Thus, adjuvant chemotherapy is not routinely given in this setting unless the risk of recurrence is heightened.

ASCO and ESMO guidelines suggest that patients with stage II CRC be stratified, reserving adjuvant chemotherapy to those at high risk $(2,3)$. High-degree risk factors for recurrence of stage II CRC are stipulated by ASCO as $<12$ dissected lymph nodes, T4 staging, instances of perforation, poorly differentiated adenocarcinoma, and signet ring cell or mucinous carcinoma. However, ESMO guidelines specify T4 staging; poorly differentiated adenocarcinoma or undifferentiated carcinoma; venous, lymphatic, or perineural invasion; initial symptoms of intestinal obstruction or bowel perforation; and <12 dissected lymph nodes as high-degree risk factors. In Japan, patients with these risk factors generally receive adjuvant chemotherapy postoperatively.

LVI is marked by freely existing malignant cells that seed lymphatic vessels or small veins, having escaped the primary tumor (8). While linked to tumor metastasis/recurrence (and perhaps worse prognosis) and cited as a prognostic factor in various cancers, including those of breast (9) and prostate (10), the impact of LVI on CRC recurrence or prognosis remains unclear. Some researchers have determined that vascular invasion confers a poor prognosis $(11,12)$, whereas

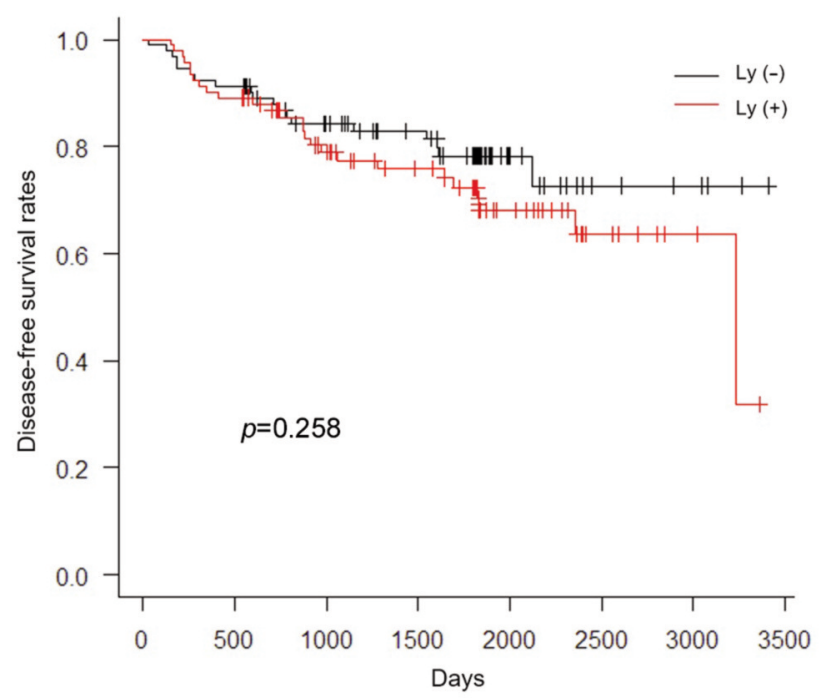

Figure 6. Disease-free survival in patients with stage II CRC, positive (+) or negative (-) for lymphatic invasion.

others have failed to identify any bearing on prognosis (13, 14). Such differences may be due to disparate population samplings or methods of analysis. Herein, we used propensity score matching to minimize the potential for confounding in group analyses. Because venous and lymphatic invasion are seldom differentiated, the potential differences are not fully appreciated. A previous study suggested that in CRC, positive venous invasion significantly worsened 5-year DFS, but lymphatic invasion did not affect prognosis (15). In this study, we focused on lymphatic invasion and venous invasion respectively limited in stage II CRC patients to explore the possibility of omitting postoperative adjuvant chemotherapy.

Our data have shown that OS and DFS in patients with stage II CRC are significantly influenced by venous invasion. Recurrent disease, and thus a poorer prognosis, is therefore more likely in the presence ( $v s$. absence) of venous invasion. Postoperative adjuvant chemotherapy may then be appropriate under these circumstances to improve patient outcomes. On the other hand, lymphatic invasion had no significant impact on disease recurrence or prognosis in this clinical context.

By immunohistochemcal means, Liang P. et al. have established distinct associations linking lymphatic invasion to nodal metastasis and venous invasion to distant metastasis (16). In patients with venous invasion, elimination of intravascular cancer cells with adjuvant chemotherapy may reduce postoperative distant metastases. We routinely performed D3 nodal dissections for stage II CRC, so any potential lymphatic spread (including lymphatic seeding) is apt to be resected and controlled. Ultimately, lymphatic 
invasion had no significant impact on recurrence or prognosis of stage II CRC in our patients. For patients with stage II CRC who have had adequate lymph node dissection, a lymphatic invasion result alone suggests that there is little need for adjuvant chemotherapy, which may be omitted.

The incidence of LVI in previously published studies of stage II CRC ranges from 5.2-30.3\% (12, 14, 17-19). We documented venous invasion in $61.3 \%$ of our cohort and lymphatic invasion in only $14.8 \%$. This sizeable disparity, relative to other reported data, may be explained by differences in targeted groups and tumors, criteria for determining vascular invasion, and immunohistochemical support. In addition to routine histopathological assessments by hematoxylin and eosin (H\&E) stain, immunohistochemistry was an added discretionary measure, enabling more accurate diagnosis of vascular invasion $(16,20)$. This helped distinguish between venous and lymphatic invasion, which is often difficult in H\&Estained sections (21), no doubt bolstering the diagnostic rate at our institution.

There were certain limitations to this study, the first being the ability to discern venous and lymphatic invasion in histological preparations. The retrospective nature of this study was yet another issue. Although propensity score matching served to minimize bias, complete randomization was lacking. The premise that adjuvant chemotherapy may benefit patients with proven vascular invasion of stage II CRC must be fully tested in randomized, controlled clinical trials.

\section{Conclusion}

In patients with stage II CRC, venous invasion bodes poorly for prognosis, so adjuvant chemotherapy should be considered. After curative lymph node dissection, lymphatic invasion assumes no prognostic influence, so adjuvant chemotherapy may not be necessary with lymphatic invasion alone.

\section{Conflicts of Interest}

The Authors have no competing interests to declare with regard to this study.

\section{Author's Contributions}

MK drafted the manuscript. YH and SY supervised and reviewed its content. TI, HK, MA, SI, AK, TF, and SS reviewed the content as well. All authors have read and approved the final deliverable.

\section{Consent for Publication}

All patients have agreed to the use of their personal medical data for research and publication.

\section{Acknowledgements}

The Authors wish to thank BioMed Proofreading LLC for English copyediting.

\section{References}

1 Hashiguchi Y, Muro K, Saito Y, Ito Y, Ajioka Y, Hamaguchi T, Hasegawa $K$, Hotta $K$, Ishida $H$, Ishiguro $M$, Ishihara $S$, Kanemitsu Y, Kinugasa Y, Murofushi K, Nakajima TE, Oka S, Tanaka T, Taniguchi H, Tsuji A, Uehara K, Ueno H, Yamanaka T, Yamazaki K, Yoshida M, Yoshino T, Itabashi M, Sakamaki K, Sano K, Shimada Y, Tanaka S, Uetake H, Yamaguchi S, Yamaguchi N, Kobayashi H, Matsuda K, Kotake K and Sugihara $\mathrm{K}$, Japanese Society for Cancer of the Colon and Rectum: Japanese society for cancer of the colon and rectum (jsccr) guidelines 2019 for the treatment of colorectal cancer. Int J Clin Oncol 25(1): 1-42, 2020. PMID: 31203527. DOI: $10.1007 /$ s10147-019-01485-z

2 Benson AB, Schrag D, Somerfield MR, Cohen AM, Figueredo AT, Flynn PJ, Krzyzanowska MK, Maroun J, McAllister P, Van Cutsem E, Brouwers M, Charette M and Haller DG: American society of clinical oncology recommendations on adjuvant chemotherapy for stage ii colon cancer. J Clin Oncol 22(16): 3408-3419, 2004. PMID: 15199089. DOI: 10.1200/JCO. 2004.05.063

3 Schmoll HJ, Van Cutsem E, Stein A, Valentini V, Glimelius B, Haustermans K, Nordlinger B, van de Velde CJ, Balmana J, Regula J, Nagtegaal ID, Beets-Tan RG, Arnold D, Ciardiello F, Hoff P, Kerr D, Köhne CH, Labianca R, Price T, Scheithauer W, Sobrero A, Tabernero J, Aderka D, Barroso S, Bodoky G, Douillard JY, El Ghazaly H, Gallardo J, Garin A, Glynne-Jones R, Jordan K, Meshcheryakov A, Papamichail D, Pfeiffer P, Souglakos I, Turhal $\mathrm{S}$ and Cervantes A: Esmo consensus guidelines for management of patients with colon and rectal cancer. A personalized approach to clinical decision making. Ann Oncol 23(10): 2479-2516, 2012. PMID: 23012255. DOI: $10.1093 /$ annonc/mds236

4 Gray R, Barnwell J, McConkey C, Hills RK, Williams NS, Kerr DJ and Group QC: Adjuvant chemotherapy versus observation in patients with colorectal cancer: A randomised study. Lancet 370(9604): 2020-2029, 2007. PMID: 18083404. DOI: 10.1016/S0140-6736(07)61866-2

5 Tournigand $\mathrm{C}$ and de Gramont A: Chemotherapy: Is adjuvant chemotherapy an option for stage ii colon cancer? Nat Rev Clin Oncol 8(10): 574-576, 2011. PMID: 21912416. DOI: 10.1038/ nrclinonc.2011.139

6 Gill S, Loprinzi CL, Sargent DJ, Thomé SD, Alberts SR, Haller DG, Benedetti J, Francini G, Shepherd LE, Francois Seitz J, Labianca R, Chen W, Cha SS, Heldebrant MP and Goldberg RM: Pooled analysis of fluorouracil-based adjuvant therapy for stage ii and iii colon cancer: Who benefits and by how much? J Clin Oncol 22(10): 1797-1806, 2004. PMID: 15067028. DOI: 10.1200/JCO.2004.09.059

7 Figueredo A, Charette ML, Maroun J, Brouwers MC and Zuraw L: Adjuvant therapy for stage ii colon cancer: A systematic review from the cancer care Ontario program in evidence-based care's gastrointestinal cancer disease site group. J Clin Oncol 22(16): 3395-3407, 2004. PMID: 15199087. DOI: 10.1200/ JCO.2004.03.087 
8 Zhong JW, Yang SX, Chen RP, Zhou YH, Ye MS, Miao L, Xue ZX and Lu GR: Prognostic value of lymphovascular invasion in patients with stage iii colorectal cancer: A retrospective study. Med Sci Monit 25: 6043-6050, 2019. PMID: 31408453. DOI: 10.12659/MSM.918133

9 Aleskandarany MA, Sonbul SN, Mukherjee A and Rakha EA: Molecular mechanisms underlying lymphovascular invasion in invasive breast cancer. Pathobiology 82(3-4): 113-123, 2015. PMID: 26330352. DOI: 10.1159/000433583

10 Jeong JU, Nam TK, Song JY, Yoon MS, Ahn SJ, Chung WK, Cho IJ, Kim YH, Cho SH, Jung SI and Kwon DD: Prognostic significance of lymphovascular invasion in patients with prostate cancer treated with postoperative radiotherapy. Radiat Oncol J 37(3): 215-223, 2019. PMID: 31591870. DOI: 10.3857/roj. 2019.00332

11 Horn A, Dahl O and Morild I: The role of venous and neural invasion on survival in rectal adenocarcinoma. Dis Colon Rectum 33(7): 598-601, 1990. PMID: 2361429. DOI: 10.1007/ BF02052215

12 Lim SB, Yu CS, Jang SJ, Kim TW, Kim JH and Kim JC: Prognostic significance of lymphovascular invasion in sporadic colorectal cancer. Dis Colon Rectum 53(4): 377-384, 2010. PMID: 20305435. DOI: 10.1007/DCR.0b013e3181cf8ae5

13 Minsky BD, Mies C, Recht A, Rich TA and Chaffey JT: Resectable adenocarcinoma of the rectosigmoid and rectum. ii. The influence of blood vessel invasion. Cancer 61(7): 14171424, 1988. PMID: 3345494. DOI: 10.1002/10970142(19880401)61:7<1417::aid-cncr2820610723>3.0.co;2-9

14 Artac M, Turhal NS, Kocer M, Karabulut B, Bozcuk H, Yalcin $\mathrm{S}$, Karaagac M, Gündüz S, Isik N and Uygun K: Do high-risk features support the use of adjuvant chemotherapy in stage ii colon cancer? A Turkish oncology group study. Tumori 100(2): 143-148, 2014. PMID: 24852857. DOI: 10.1700/1491.16397

15 Ishikawa D, Takasu C, Kashihara H, Nishi M, Tokunaga T, Higashijima J, Yoshikawa K, Yasutomo K and Shimada M: The significance of microrna-449a and its potential target hdac1 in patients with colorectal cancer. Anticancer Res 39(6): 28552860, 2019. PMID: 31177123. DOI: 10.21873/anticanres.13414
16 Liang P, Nakada I, Hong JW, Tabuchi T, Motohashi G, Takemura A, Nakachi $T$ and Kasuga $T$ : Prognostic significance of immunohistochemically detected blood and lymphatic vessel invasion in colorectal carcinoma: Its impact on prognosis. Ann Surg Oncol 14(2): 470-477, 2007. PMID: 17103258. DOI: 10.1245/s10434-006-9189-3

17 Ghosh P, Tie J, Muranyi A, Singh S, Brunhoeber P, Leith K, Bowermaster R, Liao Z, Zhu Y, LaFleur B, Tran B, Desai J, Jones I, Croxford M, Jover R, Goel A, Waring P, Hu S, Teichgraber V, Rohr UP, Ridder R, Shanmugam K and Gibbs P: Girdin (giv) expression as a prognostic marker of recurrence in mismatch repairproficient stage ii colon cancer. Clin Cancer Res 22(14): 3488-3498, 2016. PMID: 27029492. DOI: 10.1158/1078-0432.CCR-15-2290

18 Peng SL, Thomas M, Ruszkiewicz A, Hunter A, Lawrence M and Moore J: Conventional adverse features do not predict response to adjuvant chemotherapy in stage ii colon cancer. ANZ J Surg 84(11): 837-841, 2014. PMID: 24224835. DOI: 10.1111/ans.12444

19 Lin HH, Chang YY, Lin JK, Jiang JK, Lin CC, Lan YT, Yang SH, Wang HS, Chen WS, Lin TC and Chang SC: The role of adjuvant chemotherapy in stage ii colorectal cancer patients. Int J Colorectal Dis 29(10): 1237-1243, 2014. PMID: 25024041. DOI: $10.1007 / \mathrm{s} 00384-014-1943-6$

20 Barresi V, Reggiani Bonetti L, Vitarelli E, Di Gregorio C, Ponz de Leon $\mathrm{M}$ and Barresi G: Immunohistochemical assessment of lymphovascular invasion in stage $\mathrm{i}$ colorectal carcinoma: Prognostic relevance and correlation with nodal micrometastases. Am J Surg Pathol 36(1): 66-72, 2012. PMID: 21989343. DOI: 10.1097/PAS .0b013e31822d3008

21 Compton C, Fenoglio-Preiser CM, Pettigrew N and Fielding LP: American joint committee on cancer prognostic factors consensus conference: Colorectal working group. Cancer $88(7)$ : 1739-1757, 2000. PMID: 10738234. DOI: 10.1002/(sici)10970142(20000401)88:7<1739::aid-cncr30>3.0.co;2-t

Received October 11, 2020

Revised October 23, 2020

Accepted October 27, 2020 